\title{
Making it Work: A Study of Australian Expatriate Language and Cultural Strategies for the Workplace in Japan
}

\author{
Sean O'Connell
}

The University of Queensland

\section{Introduction}

Australia has maintained a steady and strong business relationship with Japan for over three decades. In fact, Japan ranks first in terms of important export markets ${ }^{1}$ for Australia. As a result, it can be assumed that, on a micro-level, the possibility of more expatriates from Australia being stationed in Japan will increase to facilitate business communication and transactions between Australian and Japanese companies. With the creation of multinational workplaces, including Australians and Japanese working together in Japan, comes an increasing necessity for Australian expatriates to have linguistic and cultural competence. While this has been identified in intercultural communication research ${ }^{2}$, the implementations of such findings related to Japanese language proficiency and how it benefits Australian-Japanese workplace communication is seemingly sporadic despite the investment into Japanese language education by Australia.

Japanese language and Japan-related studies have been popular in Australia ${ }^{3}$ for over 20 years. According to the Japan Foundation ${ }^{4}$, Japanese language learners in Australia were estimated to number at around 380,000 in 2003, an 80,000 increase on the numbers recorded in 1998. Additionally, other research shows that Japanese is regarded as one of the top four Asian languages to be taught in Australia's LOTE (Languages Other Than English) education ${ }^{5}$, with the motivation to learn Japanese at tertiary level linked to the view of career prospect enhancement. However, this type of research outwardly fell short in identifying the effectiveness of having Japanese proficiency, and more importantly, its role in enhancing cultural competence (i.e. the ability to function effectively in a host culture) in business communication. Indeed, a number of intercultural communication researchers $^{6}$ argue that the level of second-language proficiency among expatriates is a determining factor in achieving effective intercultural workplace communication. While this notion may seem obvious, there are few pieces of empirical evidence that show how

\footnotetext{
${ }^{1}$ Department of Foreign Affairs \& Trade, 'Australia-Japan Economic Framework.'

${ }^{2}$ Irwin, H., 'Communicating with Asia.; March, R.M., 'Working for a Japanese Company. Insights into the Multicultural Workplace.'; Kubota M., 'Factors Affecting Japanese Proficiency Levels in Native English Speakers.'

${ }^{3}$ Lee, D.Y., 'Japanese Education in the Australian Context.'; Ramzan, Y., 'Japanese Language Instruction in a Multicultural Context: promoting Citizenship and Interculturality.

${ }^{4}$ Japan Foundation, 'Survey Report on Japanese Language Education Abroad 2003.'

${ }^{5}$ Rudd, K., 'Asian Languages and Australia's Economic Future. A Report Prepared for the Council of Australian Governments on a Proposed National Asian Languages/Studies Strategy for Australian Schools.'

${ }^{6}$ Du-Babcock, B., \& Babcock, R., 'Patterns of expatriate-local personnel communication in multinational corporations.'

Fisher, G.B. \& Härtel, C.E.J., 'Cross-cultural effectiveness of Western expatriate - Thai client interactions: Lessons learned for IHRM

research and theory'; Selmer, J., Language Ability and Adjustment: Western Expatriates in China.
} 
Australians with second-language and cultural competence achieve effective business communication.

Accordingly, this paper seeks to contribute to broadening knowledge specific to an Australian-Japanese intercultural business communication context by examining the effectiveness of Australian expatriates with high Japanese language proficiency and cultural competence.

\section{Researcher's Role}

In my role as an intercultural communication researcher, I have always related my own experiences to the context of my research. In the discussion presented in this paper, it is therefore important to explain the impetus behind my research. Like many of the participants in my Masters (previous) and $\mathrm{PhD}$ (present) research, my ties with the Japanese language and culture began at high school. Now, as an interpreter, intercultural communication trainer and researcher, being mindful of communication style and cultural differences, and how best to negotiate them to achieve communication goals, is vital. Consequently, the findings presented in this paper, as well as my present research in its entirety, not only serve to expand current knowledge, but also provide an opportunity for self-reflection regarding my own communication strategies as an expatriate in Japan.

\section{Focus}

This paper focuses on a description of findings from my previous and present research. Specifically, it illustrates the importance and impact of high Japanese proficiency and cultural competence on workplace communication between Australian expatriates and their Japanese co-workers. The paper is organised as follows:

a) background information regarding the Australia-Japan business relationship, Japanese education in Australia, and the researcher's role;

b) explanation of the research framework (high context/low context and communication accommodation theories and expatriate-local personnel studies);

c) description of the previous and present study methodology;

d) discussion of findings from both studies; and

e) conclusion. 


\section{Research Framework}

This section describes two theoretical frameworks used in my research: High and Low Context Communication, and Communication ${ }^{7}$ Accommodation Theor ${ }^{8}$. It then gives a brief review of the current expatriate and local personnel research literature.

\section{High and Low Context Communication}

For the past thirty years, the High and Low Context Communication context spectrum has been used to examine communication style differences and how such differences affect the communication process in intercultural contexts. People communicating in a high-context environment, such as Japan, receive more of the information from within the context. Subsequently, less of the meaning of a message is provided verbally or explicitly. In contrast, in low-context cultures, including Australia, New Zealand, Canada and the U.S., the verbal part of the message itself contains more of the information and the majority of the transmitted information is embedded in explicit verbal codes.

However, despite the common assumption that these English speaking nations share similar styles of communication within the low-context spectrum, there are significant differences that warrant a specific investigation to avoid inaccurate generalisations. For example, differences in expressions of achievement and status as well as conflict resolution styles are evident between Australians and Americans. Australians will generally avoid giving compliments or recognising status, whereas Americans value this style in business. Furthermore, while both appreciate explicit, verbalexpression, Australians thrive more on honesty, colourful statements and shifts in subject as part of conflict resolution than smooth and patterned expressions used by Americans. ${ }^{9}$

Considering my research context, this framework is particularly relevant as Japan and Australia sit at opposite ends of this polar dimension. In Australia, it is imperative that the sender of a message encodes it clearly as they tend not to search for information from the environment. The receiver of the message is responsible for seeking confirmation and clarity should the verbal message be unclear. Conversely, the communication flow and subsequent role expectations differ in the high-context Japanese culture. In other words, the verbal part of the communication may be vague or indirect as both sides are expected to analyse the context to complete the communication process.

\footnotetext{
Hall, E.T. \& M.R., 'Hidden Differences: Doing Business with the Japanese.'

${ }^{8}$ Giles, H., 'Accent mobility. A model and some data.'

${ }^{9}$ Renwick, G.W., 'A fair go for all: a guide for Australians and Americans'
} 


\section{Communication Accommodation Theory}

This theory is used to explain the adjustments in speech style during interactions as well as communication behaviours, attitudes, and perceptions. There are four main focal points: approximation strategies, discourse management, interpretability and interpersonal control. In my present research it is used to analyse the workplace communication strategies of Australian expatriates with high Japanese proficiency and cultural competence when communicating with their Japanese co-workers. Naturally, to test each of the four main foci in its entirety would be far beyond the scope of my present research.

Consequently, one focal point is used: approximation strategies (convergence, divergence and maintenance). Convergence means that one person in the communication process adapts his or her normal style of communication to closely match that of the other person. This could involve, for example, copying para-verbally (tone, speed etc.) or style (directness or indirectness). This is usually done to increase the sense of similarity in order to gain consensus or cooperation. Divergence, on the other hand, refers to an opposite style of communication. For example, where one interlocutor uses an indirect style of communication, the other may diverge by intentionally adopting a direct style. Finally, maintenance means that a person neither converges nor diverges, but instead maintains their usual style of communication.

\section{Expatriate and Local Personnel Communication}

Expatriate studies are primarily located within the field of intercultural communication. Such studies have received significant attention over the past decade due to the advancement of globalisation and the issues of international communication born from it. Nevertheless, a dominant tendency to focus on issues of cultural adjustment, management performance and effectiveness ${ }^{10}$ is evident. Conversely, workplace communication studies have not gained as much attention. This is in spite of a strong claim by intercultural communication researchers ${ }^{11}$ that the impact of second language proficiency and cultural competence is largely due to the need for expatriates to accommodate their methods and styles of communication to the host culture for ultimate effectiveness.

While limited, the notion of accommodation is a common theme within studies of expatriates with high second-language proficiency. For example, language proficiency has been identified as a way to attain intercultural effectiveness in communication between Western expatriates and Chinese local staff ${ }^{12}$. In other words, high secondlanguage (Chinese) proficiency was found to enhance expatriate adjustment due to an

\footnotetext{
${ }^{10}$ Birdseye, M.G., \& Hill, J.S., 'Individual, Organizational Work and Environmental Influences on Expatriate Turnover Tendencies: An Empirical Study.'; Fisher, G.B. \& Härtel, C.E.J., op. cit.

${ }^{11}$ Selmer, J., op. cit.

${ }^{12}$ Ibid. 
increase in trust and ability to explore the host business culture through language.

Specific reference to communication accommodation and high/low context communication differences is evident in another study of Western expatriates (British and American) in Taiwan ${ }^{13}$. Results expounded that high second-language proficiency and cultural intelligence created a higher expectation by the local personnel for expatriates to follow social norms and rules of the host country. Put simply, expatriates are seen more as insiders because they are able to pick up on the subtleties and deep structured meaning of what is said. Consequently, it was found they consistently accommodated towards low-context communication in objective professional topic areas and highcontext communication in interpersonal and private topics, especially when conversations were related to face-threatening issues. This illustrates one of the characteristics of accommodation, or in this case, expectations to follow suit or converge.

\section{The Study: Methodology and Participants}

Using a mixed-method approach, both pieces of research began with a survey of a large sample from which a smaller sample was selected for a qualitative style of inquiry. This was done to illicit in-depth perceptions and evaluations of Japanese proficiency, cultural competence and communication accommodation from the participants.

Accordingly, this section of the paper provides: a) an explanation of the data collection tools used; b) a description of the participants in both studies; and c) an analysis of the findings in order of the research conducted.

\section{Previous Research}

The central goal was to obtain a widespread and accurate analysis of the current levels of Australian expatriate Japanese proficiency and cultural competence. It began with a questionnaire consisting of closed- and open-ended questions related to (a) basic participant profile: position, length of assignment etc.; (b) Japanese language and business culture education and training; (c) familiarity of Japanese communication style; and (d) areas that cause confusion or communication breakdown.

At first, the aim was to shed light on the amount of language and cultural training Australian expatriates received to achieve intercultural competence. However, as the research progressed, it was discovered that a relatively low amount of structured training was provided by companies. This meant that the Australian expatriates were expected to develop those skills themselves. As a result, the methodology evolved into a focus

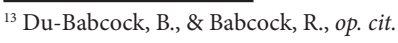


interview that centered on (a) the importance of Japanese skills and cultural competence; (b) how those skills have helped or would have helped bridge a gap; and (c) areas of Japanese communication that were confusing or hard to accept.

For the questionnaire, a total of 90 participants (50 Australian expatriates and 40 New Zealand expatriates) were secured. There were a variety of sojourn lengths among the subjects, with an average of 4.5 years, as well as an array of work they engaged in spanning trade, finance, tourism, construction and retail industries and roles from subordinate through to executive positions. For the purpose of this paper, I will limit my description to that of the Australian expatriates.

The participants were all directly involved and in contact with Japanese clients and staff. In the focus interview, 25 Australian expatriates from the original sample were selected based on the criteria as a result of being identified as having high Japanese proficiency and cultural competence. The interviews were all approximately 60 minutes in length and consisted of questions which allowed the participants to expand freely on the above-mentioned themes. In terms of Japanese proficiency evaluation, the method of evaluation differed in the previous and present research. In the previous research, the evaluation was a combination of self-evaluation by the expatriates and my observations as the researcher.

\section{Present Research}

The self-evaluation and anecdote design of the previous research revealed limitations regarding validity as perceptions from their Japanese co-workers were not sought. Accordingly, in the present research, I have sought to validate the evaluation in order to reliably identify Australian expatriates with a high level of Japanese language proficiency. This was triangulated using: 1) self-evaluation; 2) other-evaluation (Japanese coworker); and 3) my observations as a bilingual researcher. Additionally, both sides were provided with the FSI (Foreign Service Institute) scale ${ }^{14}$ as an accurate guide for Japanese evaluation. The FSI scale is made up of five levels from S1 to S5. S1 is the lowest level, signifying the ability to use simple language in Japanese such as greetings and everyday social expressions. As the level rises, so does the ability to S5, which is defined as a fully bilingual level.

The present research questionnaire also included closed- and open-ended questions; however, its focus and the participants it was distributed among differed. The participants were recruited from among three companies - two trade-related organisations (one 100\% Australian and a 50/50 joint venture) and one construction related organisation (100\% Australian-owned). In total, 12 Australian expatriates and 48

\footnotetext{
${ }^{14}$ Jones, R., The FSI oral interview.
} 
Japanese personnel participated. The questionnaire stage was also used to identify and recruit a smaller number from the original sample for the final ethnographic stage of my present research.

\section{Findings and Discussion}

Under the central theme of this paper, 'making it work', the findings are split into two sections, language proficiency and cultural competence, and workplace communication, to illustrate the impact of the Australian expatriates' Japanese language and cultural competency has on their workplace communication in Japan.

\section{Language Proficiency and Cultural Competence}

Firstly, Japanese proficiency varied in the previous research. Thorough analysis of the data from the questionnaire and interviews found that approximately $65 \%$ possessed high Japanese proficiency, whereas the remaining 35\% evaluated themselves as having only basic Japanese proficiency, such as basic greetings and other phrases for basic daily conversation. One of the expatriates labelled the two types as 'new breed' and 'old guard' expatriates. 'New breed' expatriates refers the type who have a high level of Japanese proficiency gained through LOTE and other education opportunities. The 'old guard' expatriates were described as the type that have limited Japanese proficiency and relied on in-house interpreters as link-pins in their communication with Japanese staff and clients. In spite of the existence of so-called 'old guard' expatriates, with $65 \%$ of the participants possessing high levels of Japanese, the 'new breed' expatriates were identified to have an increasingly dominant existence within the Australian expatriate dynamic.

Interestingly, when asked whether they felt knowing the characteristics of Japanese business communication (e.g. decision-making consensus and communication style differences) was necessary to function effectively in Japan, all participants responded affirmatively. As a result, it was clearly evident that their level of cultural competence was high. Of particular significance was the $85 \%$ response recognising high and low context differences by the 'new breed' expatriates. This was further explored in the focus interviews with the following comments representative of their perspectives:

At first, I was always trying to finish their sentences for them without realising that's all they had to say as if they were expecting me to extract information from elsewhere. After five years working in this environment, I now understand that their vagueness is not actually vague, but an important part of achieving a smooth interaction by relying on the context. (Australian expatriate\#25)

Once you have the language skills to explore the cultural subtleties, you get better at 
deciphering the hidden message. Australians are a lot more verbal and explicit, but you can't always use that the same way if you want to get the message across. (Australian expatriate \#20)

Despite a four-year interval (2001-2005), the results of the present research questionnaire confirmed a continued emphasis of the importance placed on high Japanese proficiency. All of the twelve Australian expatriate participants had studied Japanese in Australia, and nine of them had been to Japan at some stage as exchange students for one year or more. Everyone except one participant self-evaluated themselves as possessing high Japanese proficiency. Using a ratio of approximately 4:1 (Japanese worker : Australian expatriate), I expected to discover some discrepancies in evaluation assuming that some of the expatriates may over-evaluate themselves. However, a comparison of the self and Japanese co-worker evaluations revealed that approximately 75\% (nine out of twelve) were placed at the S4 level, or individuals whose Japanese proficiency was equivalent to that of native-like proficiency.

Another aim of the questionnaire was to attain information regarding when both sides felt it was necessary to accommodate to a high-context style of communication. The following are examples of when it was felt necessary:

Having a high level of Japanese is such an important inroad to understanding how the culture influences the way Japanese communicate. Without my language skills I wouldn't be able to truly understand the differences and know when to adapt my normal style of communication to the Japanese style. (Australian expatriate \#5)

I find that when we converse in English we can be more verbal and explicit, but in order to maintain harmony in the workplace, I think that my Australian colleague is more effective in Japanese if he uses a Japanese-style of communication (saying less to mean more) so that we can read the context. (Japanese co-worker \#32)

It's nice to feel that my communication goals have been achieved by showing the willingness to adopt a less straight-to-the-point approach. My colleagues and clients tend to be more active and cooperative if they are allowed to guess what I mean. (Australian expatriate\#12)

\section{Workplace Communication}

In the previous research, approximately $75 \%$ of the Australian expatriates claimed that a conscious change in their normal style of communication was required in workplace communication. For example, one expatriate pointed to the effective workplace communication as 'being able to know when you should be more indirect, subtle and less-wordy, like the Japanese are, to get the message across smoothly' (Australian expatriate \#14). When asked to elaborate on this comment, the participant claimed that 
using his own direct approach invited an initial understanding but did not help to achieve cooperation.

In the present research, an average of $72 \%$ of the workplace communication was conducted in Japanese, including staff meetings, daily task discussions as well as after-work functions. Among the three organisations surveyed, two required only a limited amount of English proficiency from the Japanese staff, whereas the other organisation required an equally high proficiency in Japanese from both the expatriates and Japanese staff due to client diversity. Nonetheless, the third company participants also reported that over 75\% of its workplace communication was done in Japanese.

The level of cultural competence was found to be high, as shown by the awareness of communication accommodation issues. Results indicated a tendency by the expatriates to adopt convergent strategies in order seek cooperation from their Japanese co-workers. For example, an Australian working in a joint-venture stated: 'You can't always spell everything out verbally. That is somewhat of a wildcard that I tend not to use much if I'm seeking cooperation and understanding' (Australian expatriate \#11). Similar perspectives were derived from participants in the other organisations also indicating expectations of adjustment. For example: 'I really feel more comfortable in my communication with my Australian colleague when he uses a less direct approach and allows me to read between the lines' (Japanese co-worker \#4) and 'I know that the Australian style of communication is normally more to the point, but our communication is a lot smoother, especially when seeking mutual support and understanding, if the Australian doesn't try to spell everything out' (Japanese co-worker \#15). The above responses clearly show how the use of high Japanese proficiency impacts the cultivation of cultural competence to function effectively in their workplaces.

Although the analysis indicates a positive impact of high intercultural communication competence, there were two other important discoveries related to cultural differences that Australian expatriates still found hard to accept. One example was with reference to the concept of nemawashi. One Australian expatriate who works at a senior level in Japan for a trade-related organisation remarked that 'while most Japanese business communication and culture are comprehensible, the concept of nemawashi just doesn't make sense for Australians' (Australian expatriate \#3). This perspective was shared by $45 \%$ of the expatriate participants, saying that it seemed to be inefficient in terms of time. When asked to elaborate, one expatriate stated:

the main difficulty is the slow or lack of decision making and the need to always seek higher authority for seemingly small decisions that business people are used to making on the spot in Australia. This is perhaps due to a lack of empowerment of staff with manager titles in Japanese companies, and they seem not to have the authority to make decisions as would staff in the same position in Australian companies. (Australian expatriate \#12) 
The above comments suggest that even being able to understand the subtle nuances of Japanese communication and culture does not always mean that everything is accepted. Additionally, the use of silence was identified by approximately $85 \%$ of the Australian participants, stating that it generated confusion, especially in the first stages of their work in Japan. However, their responses suggested that long-term expatriates now see it as merely a non-response mode of communication. The lack of explicit signals in general was another part of non-verbal communication that many of the participants saw as part of the high context versus low context differences between the countries.

\section{Conclusion}

The objective of this paper was to describe how high levels of Japanese proficiency and cultural competence help Australian expatriates to 'make it work' in terms of workplace communication. In particular, it focused on the perceptions and evaluations of intercultural communication competence and how cultural differences were explored and recognised through the use of these competencies. The first section aimed to show how this research relates to the product of LOTE (Japanese) education in Australia based on the fact that few studies have shown how the priority placed on Japanese language education is producing positive results to enhance intercultural workplace communication.

The second section provided two appropriate theoretical frameworks to analyse the development of cultural competence through high Japanese proficiency. This was clearly shown by responses in both studies that indicated the differences in communication styles, i.e. high versus low context communication. A strong awareness of the need to adapt to a high context style to improve both the ease and efficiency of communication was evident from the responses of the Australian expatriates. In other words, Japanese proficiency in fact helps to explore cultural differences between the expatriates and their Japanese personnel. This finding not only supports previous findings in other studies mentioned, but it also contributes to the notion that, without high Japanese proficiency, sufficient interpretation of how communication styles between Australians and Japanese differ cannot be made.

In terms of methodology and findings, the mixed method approach proved successful and valid for a number of reasons. Firstly, a mixture of open- and closedended questions made it possible to identify a significant number of 'new breed' expatriates. Furthermore, this approach clearly illustrated how language proficiency positively impacted the development of cultural competence. As shown in the findings section, the common tone of having to 'read between the lines' or to use indirect, subtle approaches to communication to gain cooperation show the awareness of high/low context communication. Secondly, by incorporating Japanese co-worker evaluations and perceptions in the present study, a reliable evaluation design was achieved to validate the data. Furthermore, the perceptions regarding communication accommodation were 
forthcoming from both sides. Findings from other expatriate studies mentioned in this paper also hold true for my research regarding the expectation by local personnel. Put simply, the higher the level of Japanese is, the more expatriates are expected to follow suit in relation to social and cultural norms of the host nation.

Considering the findings of these two pieces of research, the potential of my research to contribute to Japanese studies in Australia is significant. However, it should be mentioned here that, without further development of this research, the findings presented will remain limited in terms of validity and reliability. As such, the first stage questionnaire results will now be used in the ethnographic stage of my current $\mathrm{PhD}$ project. Two of the three organisations from the original sample will participate. As the researcher, I will visit both organisations 2-3 times per week for 3-4 hours to observe the workplace communication between one Australian expatriate and four Japanese co-workers. It is anticipated that this in-depth participant observation, supported by live verbal data, observation of non-verbal communication and in-depth interviews, will allow for a rich, descriptive analysis of the communication strategies employed by Australian expatriates to facilitate effective workplace communication with their Japanese co-workers.

In conclusion, this paper has clearly elucidated how this research can contribute to the broadening of knowledge in the field of intercultural communication through rich, context specific (Australian-Japanese workplace communication) data. It supports the call for research into communication accommodation skills as a workplace communication strategy in the Japanese language. As a result, a general proposition that can be offered from the findings of the two studies is that high Japanese proficiency positively affects an expatriate's ability to recognise differences in more depth, thus giving them the cultural competence required to bridge them.

\section{References}

Birdseye, M. G., \& Hill, J. S., 'Individual, Organizational Work and Environmental Influences on Expatriate Turnover Tendencies. An Empirical Study.', Journal of International Business Studies, vol. 26, no. 4, 1995, pp.787-803.

Department of Foreign Affairs \& Trade, Australia-Japan Economic Framework. Retrieved 5 May 2006, from http:// www.dfat.gov.au/geo/japan/trade/framework.html .

Du Babcock, B., \& Babcock, R., 'Patterns of expatriate-local personnel communication in multinational corporations', Journal of Business Communication, vol. 33, no. 2, 1996, pp. 141-164.

Fisher, G.B. \& Härtel, C.E.J., 'Cross-cultural effectiveness of Western expatriate-Thai client interactions: Lessons learned for IHRM research and theory', Cross-Cultural Management: An International Journal, vol.10, no. 4, 2003, pp. 3-28. 
Giles, H., 'Accent mobility. A model and some data', Anthropological Linguistics, vol. 15, 1973, pp. 87-105.

Hall, E.T. \& M.R., Hidden Differences: Doing Business with the Japanese (New York: Anchor Books, 1990).

The Japan Foundation, Survey Report on Japanese Language Education Abroad 2003 (Urawa: The Japan Foundation, 2004).

Kubota M., 'Factors Affecting Japanese Proficiency Levels in Native English Speakers', ASAA e-journal of Asian linguistics \& language teaching, issue 5, 2003. Retrieved 14 February 2006, from http://www.arts.unsw.edu.au/languages/asaa_ejournal.

Lee, D.Y., 'Japanese Education in the Australian Context', paper presented to the 15th Biennial Conference of the Asian Studies Association of Australia, Canberra, 29 June - 2 July 2004.

March, R.M., Working for a Japanese Company. Insights into the Multicultural Workplace (London: Kodansha Europe, 1996).

Ramzan, Y., 'Japanese Language Instruction in a Multicultural Context: promoting Citizenship and Interculturality', paper presented to the 15th Biennial Conference of the Asian Studies Association of Australia, Canberra, 29 June - 2 July 2004.

Renwick, G.W., A Fair Go for All: A Guide for Australians and Americans (USA: Intercultural Press Inc., 1991).

Rudd, K., Asian Languages and Australia's Economic Future. A Report Prepared for the Council of Australian Governments on a Proposed National Asian Languages/Studies Strategy for Australian Schools (Brisbane: Queensland Government Printer, 1994).

Selmer, J., 'Language Ability and Adjustment: Western Expatriates in China', Thunderbird International Business Review, vol.48, no.3, pp. 347-368. Retrieved 18 August 2006, from http://www.interscience.wiley.com . 